(c) American Dairy Science Association, 2007.

\title{
The Effect of Solids Dilution Rate and Oil Source on Trans C18:1 and Conjugated Linoleic Acid Production by Ruminal Microbes in Continuous Culture
}

\author{
A. A. AbuGhazaleh ${ }^{1}$ and W. R. Buckles \\ Department of Animal Science, Food, and Nutrition, Southern Illinois University, Carbondale 62901
}

\begin{abstract}
The objective of this study was to evaluate the effect of solids dilution rate (SDR) and oil source [soybean oil (SBO) or linseed oil (LSO)] on the ruminal production of trans C18:1 and conjugated linoleic acid (CLA). A dual-flow continuous culture system consisting of 4 fermenters was used in a $4 \times 4$ Latin square design with a factorial arrangement of treatments over 4 consecutive periods of $10 \mathrm{~d}$ each. Treatment diets (50:50 forage to concentrate) were fed at $120 \mathrm{~g} / \mathrm{d}$ of dry matter (DM) in 3 equal portions. The concentrate mix contained $1 \%$ fish oil and either $2 \%$ SBO or $2 \%$ LSO on a DM basis. Treatments were as follows: 1 ) SBO at $6 \% / \mathrm{h}$ SDR, 2) SBO at $3 \% / \mathrm{h}$ SDR, 3) LSO at $6 \% / \mathrm{h}$ SDR, and 4) LSO at $3 \% / \mathrm{h}$ SDR. The oil source by SDR interaction was not significant for trans C18:1 and CLA fatty acids. The concentrations of trans C18:1 and vaccenic acid were greater in effluents when diets were supplemented with SBO vs. LSO (37.11 vs. 34.09 and 32.71 vs. $29.70 \mathrm{mg} /$ $\mathrm{g}$ of DM, respectively) and at high SDR than low SDR (37.60 vs. 33.61 and $32.72 \mathrm{vs.} 29.61 \mathrm{mg} / \mathrm{g}$ of DM, respectively). The concentration of cis-9, trans-11 CLA in effluents was also greater with SBO than LSO (0.81 vs. $0.40 \mathrm{mg} / \mathrm{g}$ of DM) supplementation and at high SDR than low SDR (0.68 vs. $0.54 \mathrm{mg} / \mathrm{g}$ of DM). Biohydrogenation of linoleic acid and linolenic acid increased at higher SDR within each oil treatment. Based on these results, SBO supplementation at high SDR enhances ruminal production of vaccenic acid, and therefore could potentially enhance cis-9, trans-11 CLA in milk fat through synthesis by $\Delta^{9}$-desaturase.
\end{abstract}

Key words: oil source, solids dilution rate, conjugated linoleic acid, trans fatty acid

\section{INTRODUCTION}

Conjugated linoleic acids (CLA) are a mixture of geometric and positional isomers of linoleic acid with conju-

Received June 19, 2006.

Accepted October 16, 2006.

${ }^{1}$ Corresponding author: aabugha@siu.edu gated unsaturated double bonds. Isomers of CLA have a wide range of beneficial effects, such as anticarcinogenic, antiatherogenic, antidiabetic, and antiobesity (Bauman et al., 2001). The major CLA isomer, cis-9, trans-11 (c9t11), is synthesized either in the rumen as an intermediate in the biohydrogenation (BH) of linoleic acid or in the tissues by $\Delta^{9}$-desaturase from vaccenic acid (VA; trans-11 C18:1), an intermediate in ruminal BH of both linoleic and linolenic acids (Harfoot and Hazlewood, 1988). Piperova et al. (2002) reported that approximately $90 \%$ of $c 9 t 11$ CLA appearing in milk fat is synthesized in the mammary gland; thus, many efforts have addressed ways to increase VA flow from the rumen. The factors affecting the flow of CLA and trans C18:1, VA in particular, to the duodenum as a result of ruminal $\mathrm{BH}$ need to be elucidated to increase CLA concentration in milk and meat of ruminants used for human consumption.

Several researchers have reported an increase in milk VA and $c 9 t 11$ CLA when soybean oil (SBO), sunflower oil, linseed oil (LSO), and fish oil (FO) were added to dairy cow diets (Kelly et al., 1998; Chouinard et al., 2001; AbuGhazaleh et al., 2003b; Loor et al., 2005). High concentrations of VA in the duodenal digesta have been reported for ruminants consuming diets with either linoleic or linolenic acids as the major unsaturated fatty acids (FA; Sackmann et al., 2003). However, the production of VA and $c 9 t 11$ CLA in response to dietary oil supplements high in linoleic and linolenic acids has not been always consistent. Kelly et al. (1998) showed that dietary supplementation with vegetable oils high in linoleic acid, rather than linolenic acid, resulted in the greatest increase in concentration of $c 9 t 11$ CLA in milk fat. AbuGhazaleh et al. (2003b) and Ward et al. (2002) also reported highest milk VA and $c 9 t 11$ CLA concentrations with diets supplemented with linoleic acid compared with linolenic acid oil source. However, Loor et al. (2004b, 2005) and Chow et al. (2004) reported no difference in VA and $c 9 t 11$ CLA concentrations when sunflower oil and LSO were compared in vivo and in vitro. AbuGhazaleh et al. (2002) demonstrated that the increases in milk c9t11 CLA 
and VA concentrations were higher when diets rich in linoleic acid are supplemented with FO.

Solids retention time is known to modulate ruminal fermentation and microbial growth, which could lead to an alteration in the $\mathrm{BH}$ of unsaturated FA. There are limited data addressing the effect of solids retention time on trans C18:1 and CLA formation. Solids dilution rate (SDR), characterized by the outflow of materials from the rumen, is estimated to be from 2 to $12 \% / \mathrm{hr}$ (Isaacson et al., 1975). The SDR can be highly variable in vivo because of differences in environment, physiological condition of the animal, dietary characteristics, level of feed intake, and many other factors. Therefore, continuous culture systems have been used to determine what effects changes in SDR, per se, have on rumen fermentation (Crawford et al., 1980a,b; Hoover et al., 1984; Martin and Jenkins, 2002; Qiu et al., 2004). Qiu et al. (2004) compared the effects of SDR of 8 and $4 \% / \mathrm{h}$ on flows of VA and CLA. The researchers noted that at high SDR, CLA flow tended to increase compared with the low SDR. Martin and Jenkins (2002) reported a higher increase in the concentrations of trans C18:1 and $c 9 t 11$ CLA in continuous cultures maintained at $0.10 \% / \mathrm{h}$ liquid dilution rate (LDR) compared with $0.05 \% / h$ LDR. Recently, AbuGhazaleh et al. (2005) also reported less trans C18:1 formation from oleic acid when culture LDR decreased from 0.10 to $0.05 \% / \mathrm{h}$.

The objective of this study was to assess the effects of SDR, oil source, and their interaction on trans C18:1, VA in particular, and $c 9 t 11$ CLA production in the rumen using a dual-flow continuous culture system.

\section{MATERIALS AND METHODS}

\section{Experimental Design}

Four dual-flow continuous culture apparatus, as described by Stern and Hoover (1990), were used in a 4 $\times 4$ Latin square with a $2 \times 2$ factorial arrangement over 4 periods of $10 \mathrm{~d}$ each. Each experimental period consisted of $7 \mathrm{~d}$ for adaptation, with the last $3 \mathrm{~d}$ for sampling. Treatments used in this study were as follows: 1) SBO at $6 \% / \mathrm{h} \mathrm{SDR}, 2) \mathrm{SBO}$ at $3 \% / \mathrm{h} \mathrm{SDR}, 3$ ) LSO at $6 \% / \mathrm{h}$ SDR, and 4$) \mathrm{LSO}$ at $3 \% / \mathrm{h}$ SDR. The 6 and $3 \%$ SDR resulted in 16.7 and $33.3 \mathrm{~h}$ of solids retention time, respectively. Treatment diets $(50 \%$ alfalfa pellets, $50 \%$ concentrate) were fed at $120 \mathrm{~g} / \mathrm{d}$ of DM in 3 equal portions at 0800,1500 , and $2100 \mathrm{~h}$. The concentrate mix contained $1 \% \mathrm{FO}$ and either $2 \% \mathrm{SBO}$ or $2 \% \mathrm{LSO}$ (DM basis; Table 1).

\section{Continuous Culture}

Ruminal fluid was obtained from a fistulated lactating Holstein cow receiving a 60:40 (forage:concentrate)
Table 1. Ingredient and chemical composition of treatment diets

\begin{tabular}{|c|c|c|c|}
\hline \multirow[b]{2}{*}{ Ingredient } & \multicolumn{2}{|c|}{ Treatment $\operatorname{diet}^{1}$} & \multirow[b]{2}{*}{$\mathrm{SE}$} \\
\hline & SBO & LSO & \\
\hline & \multicolumn{2}{|c|}{$(\%$ of $\mathrm{DM})$} & \\
\hline Alfalfa & 50.00 & 50.00 & - \\
\hline Ground corn & 22.20 & 22.20 & - \\
\hline Soybean meal, $48 \% \mathrm{CP}$ & 12.15 & 12.15 & - \\
\hline Soybean hulls & 12.00 & 12.00 & - \\
\hline Limestone & 0.60 & 0.60 & - \\
\hline Vitamin $\mathrm{A}, \mathrm{D}$, and $\mathrm{E}$ premix & 0.05 & 0.05 & - \\
\hline Soybean oil & 2.00 & 0.00 & - \\
\hline Linseed oil & 0.00 & 2.00 & - \\
\hline Fish oil & 1.00 & 1.00 & - \\
\hline \multicolumn{4}{|l|}{ Chemical composition } \\
\hline $\mathrm{CP}, \%$ & 17.00 & 16.90 & 0.07 \\
\hline $\mathrm{ADF}, \%$ & 28.00 & 27.60 & 0.29 \\
\hline NDF, \% & 38.10 & 38.60 & 0.16 \\
\hline Fatty acids, $\%$ & 5.86 & 5.96 & 0.08 \\
\hline
\end{tabular}

${ }^{1} \mathrm{SBO}=2 \%$ Soybean oil $+1 \%$ fish oil; LSO $=2 \%$ linseed oil $+1 \%$ fish oil (DM basis).

diet. Approximately $4.5 \mathrm{~kg}$ (10 lb) of ruminal content was taken from the cow $4 \mathrm{~h}$ after the morning feeding, strained through 2 layers of cheesecloth, transported to the laboratory in a sealed container, and used within $20 \mathrm{~min}$. Fermenter canisters $(1,700 \pm 12 \mathrm{~mL})$ were filled with $1,300 \mathrm{~mL}$ of rumen fluid and $400 \mathrm{~mL}$ of prewarmed buffer with urea added (Weller and Pilgrim, 1974). Solids and liquid dilution rates were adjusted, twice daily, to values of 6 or 3 and $11 \% / h$, respectively, by regulation of buffer input and filtrate removal rates. Fermenters were constantly mixed at $120 \mathrm{rpm}$ via a magnetic impeller stirrer unit maintained at $39^{\circ} \mathrm{C}$ and purged with $\mathrm{N}_{2}$ gas $(80 \mathrm{~mL} / \mathrm{min})$. Fermenter $\mathrm{pH}$ was regulated through buffer titration with either $3 \mathrm{~N} \mathrm{HCl}$ or $5 N \mathrm{NaOH}$ to maintain a $\mathrm{pH}$ between 6.3 and 6.9. The $\mathrm{pH}$ was measured daily at 0800,1500 , and $2100 \mathrm{~h}$ using a portable $\mathrm{pH}$ meter.

\section{Sample Collection and Analysis}

Effluent from each fermenter was collected into 5L plastic jugs submerged approximately three-fourths into a $4^{\circ} \mathrm{C}$ water bath. The solid and liquid effluent volumes were cataloged daily at $0800 \mathrm{~h}$ and discarded until the final $3 \mathrm{~d}$ of each period. On the last $3 \mathrm{~d}$, the solid and liquid portions were combined and homogenized on a stir plate, and a $10 \%$ volume subsample was collected and stored at $-5^{\circ} \mathrm{C}$. Subsamples from each fermenter were composited for d 8, 9, and 10. Samples were thawed in a $50^{\circ} \mathrm{C}$ water bath, transferred into $250-\mathrm{mL}$ plastic bottles, and centrifuged (Beckman J2-21, GMI Inc., Minneapolis, MN) at $36,000 \times g$ for $15 \mathrm{~min}$, after which the supernatant was removed. This process was repeated until all liquid in the thawed sample was re- 
moved. The bottle and fiber pellet were stored at -80 $\mathrm{C}^{\circ}$ for $48 \mathrm{~h}$, then freeze dried and ground to $1 \mathrm{~mm}$ using a Wiley mill (Arthur H. Thomas, Philadelphia, PA).

Samples of alfalfa pellets and concentrate were collected twice each period ( $\mathrm{d} 5$ and 10 ) and stored at $-20^{\circ} \mathrm{C}$ until analyses. Samples were freeze dried for at least $48 \mathrm{~h}$, then ground through a $2-\mathrm{mm}$ screen of a standard Wiley mill (model 3; Arthur H. Thomas) and composited by period. Composites were analyzed for $\mathrm{CP}, \mathrm{NDF}$, and ADF (AOAC, 1997).

Feed and effluent samples were methylated according to Kramer et al. (1997) and analyzed for FA on a Shimadzu GC-2010 gas chromatograph (Shimadzu Scientific Instruments, Inc., Columbia, MD) equipped with a flame-ionization detector and 100-m SP-2560 fused silica capillary column $(0.25 \mathrm{~mm}$ i.d. $\times 0.2 \mu \mathrm{m}$ film thickness; Supelco Inc., Bellefonte, PA). The helium carrier gas was maintained at a linear velocity of 23 $\mathrm{cm} / \mathrm{s}$. The oven temperature was programmed to $165^{\circ} \mathrm{C}$ for $80 \mathrm{~min}$, increased at $1.5^{\circ} \mathrm{C} / \mathrm{min}$ to $180^{\circ} \mathrm{C}$, and then increased at $5^{\circ} \mathrm{C} / \mathrm{min}$ to a final temperature of $245^{\circ} \mathrm{C}$, which was held for $9 \mathrm{~min}$. The injector and detector temperatures were set at $255^{\circ} \mathrm{C}$. Heptadecanoic acid (C17:0) was added to all samples as an internal standard after correcting for native C17:0. Peaks were identified by comparing the retention times with those of the corresponding standards (Nu-Chek Prep, Elysian, MN; Supelco; and Larodan Fine Chemicals, Malmo, Sweden).

\section{Statistical Analysis}

Data were analyzed with the PROC MIXED procedure of SAS 9.1 (SAS Institute, Cary, NC). Oil source, SDR, and their interaction were the fixed effect, whereas fermenter was the random effect in the statistical model. Least squares means and SEM are reported for all data. Significance was declared at $P<0.05$.

\section{RESULTS}

The ingredient and chemical composition of diets are shown in Table 1. Dietary treatments had similar values for CP, ADF, NDF, and total FA. The dietary oil sources were chosen because of the differences in their FA compositions (Table 2). Linoleic acid was the major FA in SBO (52.9\% of total FA), whereas linolenic acid was the major FA in LSO (55.7\%; Table 2). Daily input of major unsaturated FA varied according to diet (Table 3 ). Total daily input of oleic, linoleic, and linolenic acids represented 17, 38, and 6\% of total FA input, respectively, for diets supplemented with SBO. For the LSO diets, oleic, linoleic, and linolenic acids input represented 14, 19, and $33 \%$ of total FA input, respectively.
Table 2. Fatty acid (FA) profile of oil supplements

\begin{tabular}{lccr}
\hline $\begin{array}{l}\text { FA }(\mathrm{g} / 100 \mathrm{~g} \\
\text { of total FA) }\end{array}$ & Soybean oil & Linseed oil & Fish oil \\
\hline C14:0 & 0.07 & 0.05 & 6.79 \\
C16:0 & 10.05 & 4.58 & 16.67 \\
C18:0 & 6.21 & 6.43 & 2.62 \\
C18:1 & 23.23 & 19.15 & 15.83 \\
C18:2 & 52.86 & 14.57 & 2.20 \\
C18:3n3 & 6.65 & 55.71 & 2.24 \\
C20:5n3 & ND $^{1}$ & ND & 10.90 \\
C22:6n3 & ND & ND & 11.90 \\
\hline
\end{tabular}

${ }^{1} \mathrm{ND}=$ Not detected or detected at $<0.01$.

The $\mathrm{pH}$ in fermenters was similar for all treatments (6.74, 6.60, 6.73, and 6.54 for treatments 1 through 4 , respectively).

Except for oleic acid, oil source by SDR interaction for other FA in effluents was not significant, and therefore only main effect is discussed. The effect of treatments on trans C18:1 and CLA concentrations in effluent is presented in Table 4. The concentration of trans C18:1 in effluent was affected $(P<0.05)$ by oil source and SDR (Table 4). The trans C18:1 concentration was greater with SBO $(37.11 \mathrm{mg} / \mathrm{g}$ of DM) than LSO (34.09 $\mathrm{mg} / \mathrm{g}$ of DM) supplementation, and at 6\% SDR (37.6 $\mathrm{mg} / \mathrm{g}$ of $\mathrm{DM})$ than $3 \%$ SDR $(33.61 \mathrm{mg} / \mathrm{g}$ of DM).The concentration of VA, accounting for more than $88 \%$ of total trans $\mathrm{C} 18: 1$, was greater $(P<0.05)$ with SBO (32.71 mg/g of DM) than LSO $(29.70 \mathrm{mg} / \mathrm{g}$ of DM) supplementation and at $6 \%$ SDR $(32.72 \mathrm{mg} / \mathrm{g}$ of DM) compared with $3 \%$ SDR $(29.61 \mathrm{mg} / \mathrm{g}$ of DM). Concentrations of trans-6-8, trans-9, and trans-12 C18:1 were not affected by oil source but were greater $(P<0.05)$ at $6 \%$ SDR than at $3 \%$ SDR. Stearic acid concentration was affected only by SDR and concentration was greater $(P$ $<0.05)$ at $3 \%$ SDR $(8.27 \mathrm{mg} / \mathrm{g}$ of DM) than at $6 \%$ SDR $(6.4 \mathrm{mg} / \mathrm{g}$ of DM).

The $c 9 t 11$ CLA accounted for less than $1 \%$ of total effluent FA. Both oil source and SDR affected $c 9 t 11$

Table 3. Fatty acid inputs for treatment diets

\begin{tabular}{lcc}
\hline & \multicolumn{2}{c}{ Treatment diet $^{1}$} \\
\cline { 2 - 3 } Fatty acids input $(\mathrm{g} / \mathrm{d})$ & SBO & LSO \\
\hline C14:0 & 0.10 & 0.10 \\
C16:0 & 0.85 & 0.64 \\
C18:0 & 0.25 & 0.22 \\
C18:1 & 1.20 & 0.99 \\
C18:2 & 2.70 & 1.35 \\
C20:5n3 & 0.40 & 2.39 \\
C22:6n3 & 0.12 & 0.12 \\
Total fatty acids & 0.12 & 0.12 \\
\hline
\end{tabular}

${ }^{1} \mathrm{SBO}=2 \%$ Soybean oil $+1 \%$ fish oil; LSO $=2 \%$ linseed oil $+1 \%$ fish oil (DM basis). 
Table 4. Effect of solids dilution rate (SDR; 6 or 3\%) and oil source (SBO or LSO) on effluent fatty acids (mg/g of DM)

\begin{tabular}{|c|c|c|c|c|c|c|c|c|}
\hline \multirow[b]{3}{*}{ Fatty acid } & \multicolumn{4}{|c|}{ Treatment $^{1}$} & \multirow[b]{3}{*}{ SEM } & \multirow{2}{*}{\multicolumn{3}{|c|}{$P$-value }} \\
\hline & \multicolumn{2}{|c|}{$\mathrm{SBO}$} & \multicolumn{2}{|c|}{ LSO } & & & & \\
\hline & $6 \%$ & $3 \%$ & $6 \%$ & $3 \%$ & & Oil & SDR & Oil $\times$ SDR \\
\hline C14:0 & 1.28 & 1.33 & 1.27 & 1.29 & 0.02 & 0.35 & 0.13 & 0.49 \\
\hline C16:0 & 15.00 & 15.01 & 12.40 & 11.32 & 0.29 & 0.01 & 0.09 & 0.09 \\
\hline C18:0 & 7.13 & 8.12 & 5.67 & 8.45 & 0.54 & 0.32 & 0.01 & 0.13 \\
\hline C18:1 cis-9 & 7.65 & 9.16 & 7.25 & 7.38 & 0.17 & 0.01 & 0.01 & 0.01 \\
\hline C18:1 trans & 39.04 & 35.18 & 36.19 & 32.00 & 0.61 & 0.01 & 0.01 & 0.08 \\
\hline trans-6-8 & 1.29 & 1.15 & 1.35 & 1.00 & 0.07 & 0.53 & 0.01 & 0.15 \\
\hline trans -9 & 1.17 & 1.04 & 1.23 & 0.98 & 0.05 & 0.98 & 0.01 & 0.22 \\
\hline trans -11 & 34.33 & 31.13 & 31.06 & 28.16 & 0.46 & 0.01 & 0.01 & 0.76 \\
\hline trans -12 & 1.93 & 1.59 & 2.12 & 1.54 & 0.10 & 0.51 & 0.01 & 0.26 \\
\hline trans -16 & 0.32 & 0.28 & 0.43 & 0.33 & 0.04 & 0.08 & 0.11 & 0.53 \\
\hline $\mathrm{C} 18: 2$ cis-9 cis-12 & 4.91 & 5.95 & 2.21 & 2.69 & 0.28 & 0.01 & 0.02 & 0.34 \\
\hline C18:2 trans -11 cis -15 & 1.63 & 1.60 & 9.22 & 9.45 & 0.21 & 0.01 & 0.65 & 0.55 \\
\hline C18:3n3 & 0.81 & 0.93 & 2.28 & 2.78 & 0.07 & 0.01 & 0.01 & 0.03 \\
\hline C20:5n3 & 0.31 & 0.41 & 0.27 & 0.34 & 0.01 & 0.01 & 0.01 & 0.26 \\
\hline $\mathrm{C} 22: 6 \mathrm{n} 3$ & 0.40 & 0.51 & 0.34 & 0.45 & 0.02 & 0.01 & 0.01 & 0.08 \\
\hline CLA $^{2}$ cis -9 trans -11 & 0.94 & 0.68 & 0.41 & 0.39 & 0.02 & 0.01 & 0.01 & 0.11 \\
\hline CLA trans-10 cis- 12 & 0.04 & 0.03 & 0.01 & 0.03 & 0.01 & 0.16 & 0.85 & 0.25 \\
\hline C18:0 Keto ${ }^{3}$ & 3.77 & 3.16 & 2.81 & 2.46 & 0.21 & 0.01 & 0.04 & 0.55 \\
\hline C18:0 Hydroxy ${ }^{4}$ & 2.92 & 3.60 & 2.27 & 2.63 & 0.21 & 0.01 & 0.03 & 0.46 \\
\hline Total fatty acids & 106 & 105.8 & 108.5 & 101.2 & 2.67 & 0.79 & 0.35 & 0.38 \\
\hline
\end{tabular}

${ }^{1} \mathrm{SBO} 6 \%=2 \%$ Soybean oil $+1 \%$ fish oil at $6 \% / \mathrm{h} \mathrm{SDR}$, SBO $3 \%=2 \%$ soybean oil $+1 \%$ fish oil at $3 \% / \mathrm{h}$ SDR; LSO $6 \%=2 \%$ linseed oil $+1 \%$ fish oil at $6 \% / \mathrm{h}$ SDR; LSO $3 \%=2 \%$ linseed oil $+1 \%$ fish oil at $3 \% / \mathrm{h}$ SDR.

${ }^{2} \mathrm{CLA}=$ Conjugated linoleic acid.

${ }^{3}$ Keto stearic acid.

${ }^{4}$ Hydroxy stearic acid.

CLA concentration. Compared with LSO diets, SBO supplementation to diets resulted in greater $(P<0.05)$ $c 9 t 11$ CLA concentration $(0.40$ vs. $0.81 \mathrm{mg} / \mathrm{g}$ of $\mathrm{DM})$. Additionally, the concentration of $c 9 t 11$ CLA was greater $(P<0.05)$ at $6 \%$ SDR $(0.68 \mathrm{mg} / \mathrm{g}$ of $\mathrm{DM})$ than at $3 \%$ SDR $(0.54 \mathrm{mg} / \mathrm{g}$ of DM). No interaction occurred between oil source and SDR for CLA concentration. Oil source and SDR had no effect on trans-10 cis-12 CLA concentration in effluent.

Dietary oil source and SDR also affected the concentration of other FA in effluent (Table 4). The concentration of trans-11 cis-15 C18:2 was greater $(P<0.05)$ with LSO $(9.33 \mathrm{mg} / \mathrm{g}$ of DM) than with SBO $(1.61 \mathrm{mg} / \mathrm{g}$ of DM) supplementation. Solid dilution rate had no effect on trans-11 cis-15 C18:2 concentrations. The concentrations of keto stearic acid and hydroxy stearic acid were affected $(P<0.05)$ by oil source and SDR. Greater concentrations for keto stearic acid and hydroxy stearic acid were seen with SBO (3.46 and $3.26 \mathrm{mg} / \mathrm{g}$ of DM, respectively) than with LSO (2.63 and $2.45 \mathrm{mg} / \mathrm{g}$ of DM, respectively) supplementation. The concentration of keto stearic acid was greater at $6 \%$ SDR $(3.29 \mathrm{mg} / \mathrm{g}$ of DM) than at $3 \%$ SDR $(2.81 \mathrm{mg} / \mathrm{g}$ of DM), whereas hydroxy stearic acid concentration was higher at $3 \%$ SDR $(3.11 \mathrm{mg} / \mathrm{g}$ of DM) than at $6 \% \mathrm{SDR}(2.61 \mathrm{mg} / \mathrm{g}$ of DM).
The effect of treatments on unsaturated C18 FA BH is presented in Table 5. The $\mathrm{BH}$ of oleic, linoleic, and linolenic acids was greater $(P<0.05)$ at $6 \%$ SDR than at $3 \%$ SDR. Addition of SBO to diets did not affect linoleic acid $\mathrm{BH}$, whereas LSO addition increased linolenic acid $\mathrm{BH}$.

\section{DISCUSSION}

Soybean oil supplementation resulted in greater trans C18:1 concentration in effluent compared with LSO, which is consistent with previous findings obtained in vitro (AbuGhazaleh and Jacobson, 2007) and in vivo (AbuGhazaleh et al., 2003a). What seems evident from the current study and others (AbuGhazaleh et al., 2003a; AbuGhazaleh and Jacobson, 2007) is that more trans $\mathrm{C} 18: 1$ are produced during the ruminal $\mathrm{BH}$ of linoleic acid than linolenic acid. Reducing SDR from 6 to 3\% reduced trans C18:1 concentration in effluent. A reduction in the digesta retention time in the rumen would lead to more trans C18:1 leaving the rumen as a result of less complete $\mathrm{BH}$. The final step in $\mathrm{BH}$, reduction of trans C18:1 into stearic acid, is considered the rate-limiting step (Harfoot and Hazlewood, 1988). Few studies have looked at the effect of dilution rate on trans C18:1 formation. Martin and Jenkins (2002) 
Table 5. Effect of solids dilution rate (SDR, 6 or 3\%) and oil source (SBO or LSO) on the biohydrogenation of unsaturated $\mathrm{C} 18$ fatty acids

\begin{tabular}{|c|c|c|c|c|c|c|c|c|}
\hline \multirow[b]{3}{*}{ Fatty acid, \% } & \multicolumn{4}{|c|}{ Treatment $^{1}$} & \multirow[b]{3}{*}{ SEM } & \multirow{2}{*}{\multicolumn{3}{|c|}{$P$-value }} \\
\hline & \multicolumn{2}{|c|}{$\mathrm{SBO}$} & \multicolumn{2}{|c|}{ LSO } & & & & \\
\hline & $6 \%$ & $3 \%$ & $6 \%$ & $3 \%$ & & Oil & SDR & Oil $\times$ SDR \\
\hline C18:1 & 66.6 & 58.5 & 58.4 & 57.3 & 0.75 & 0.01 & 0.01 & 0.01 \\
\hline C18:2 & 90.5 & 88.1 & 90.7 & 88.6 & 0.40 & 0.42 & 0.01 & 0.57 \\
\hline C18:3 & 89.6 & 87.6 & 94.5 & 93.3 & 0.40 & 0.01 & 0.01 & 0.26 \\
\hline
\end{tabular}

${ }^{1} \mathrm{SBO} 6 \%=2 \%$ soybean oil $+1 \%$ fish oil at $6 \% / \mathrm{h}$ SDR; SBO $3 \%=2 \%$ soybean oil $+1 \%$ fish oil at $3 \% / \mathrm{h}$ SDR; LSO $6 \%=2 \%$ linseed oil $+1 \%$ fish oil at $6 \% / \mathrm{h}$ SDR, LSO $3 \%=2 \%$ linseed oil $+1 \%$ fish oil at $3 \% / \mathrm{h}$ SDR.

reported higher proportion of trans $\mathrm{C} 18: 1$ at $0.10 \mathrm{~h}^{-1}$ than at $0.05 \% / \mathrm{h}$ LDR when culture $\mathrm{pH}$ was maintained at 5.5. However, Qiu et al. (2004) reported a decrease in the flows of trans $\mathrm{C} 18: 1$ at $8 \% / \mathrm{h}$ SDR compared with $4 \% / \mathrm{h}$ SDR. The researchers do clarify their results, however, by suggesting that their findings may be due in part to the fact that the filtrate also contained some small feed particles, which may have partially alleviated the difference between fermenters with high and low SDR. The lower concentration of stearic acid at the $6 \% / \mathrm{h}$ SDR compared with $3 \% / \mathrm{h}$ SDR (Table 4 ) indicates that $\mathrm{BH}$ of unsaturated FA did not proceed to completion, possibly due to the reduction in solids retention time.

The primary objective of this study was to investigate the effect of oil source and SDR on VA production in the rumen. Vaccenic acid, an intermediate in the $\mathrm{BH}$ of linoleic and linolenic acids, is the substrate for $c 9 t 11$ CLA synthesis in the mammary gland by $\Delta^{9}$-desaturase (Bauman et al., 2001). Therefore, factors regulating VA synthesis and flow out of the rumen must be defined to maximize $c 9 t 11$ CLA in ruminant foods. The greater concentration of VA with the SBO compared with the LSO diets suggests that either the pathway of $\mathrm{BH}$ for linoleic acid is more efficient than that of linolenic acid in producing VA, or the FO in LSO cultures may have inhibited the reduction of trans-11 cis-15 C18:2, the major nonconjugated trans $\mathrm{C} 18: 2$ produced during the $\mathrm{BH}$ of linolenic acid into VA (Harfoot and Hazlewood, 1988), or both. Recently, AbuGhazaleh and Jenkins (2004a) suggested that docosahexaenoic acid (DHA) in FO promotes trans C18:1 and VA accumulation in rumen cultures, possibly by inhibiting the reductase enzyme in ruminal microorganisms responsible for the terminal hydrogenation of trans $\mathrm{C} 18: 1$ to stearic acid. The possibility that the lower VA concentration in LSO effluent may have resulted from the effect of DHA on reductase enzyme activity is supported by the accumulation of trans-11 cis-15 C18:2 in the LSO effluent (Table 4). Under normal conditions, trans-11 cis-15 C18:2 is reduced to VA or cis-15 C18:1 by the reductase en- zyme of rumen bacteria (Harfoot and Hazlewood, 1988). A similar accumulation in trans-11 cis-15 C18:2 was reported in vitro (AbuGhazaleh and Jacobson, 2007) and in vivo when dairy cows were fed a diet containing FO and LSO (Loor et al., 2004b). The inhibitory effect of DHA on the reduction of trans C18:1 into stearic acid may also explain the higher trans $\mathrm{C} 18: 1$ concentration seen in this study compared with other in vitro (Troegeler-Meynadier et al., 2003; Qiu et al., 2004) and in vivo (Piperova et al., 2002; Loor et al., 2004a, 2005) studies.

Addition of linoleic and linolenic acids has been shown to increase VA concentration in rumen batch cultures (Troegeler-Meynadier et al., 2003; AbuGhazaleh and Jacobson, 2007), rumen digesta (AbuGhazaleh et al., 2003a), duodenal lipids (Loor et al., 2005), and milk fat (Chouinard et al., 2001). However, the level of increase in VA concentration with dietary linoleic and linolenic acids has not been always consistent. Although higher VA concentrations in milk fat (Chouinard et al., 2001; Ward et al., 2002) and rumen digesta (AbuGhazaleh et al., 2003a) were reported with dairy cows fed oils high in linoleic acid, Loor et al. (2004b, 2005) reported no difference in the duodenal flow of VA in dairy cows fed LSO and sunflower oil at $5 \%$ of dietary DM. Additionally, Chow et al. (2004) reported a similar increase in VA concentration in batch cultures when sunflower oil and LSO were added at $8 \%$ of feed DM. Discrepancies between these studies may have resulted from the presence of other unsaturated FA (primarily linoleic acid) in the linolenic acid diets, differences in diet composition, and (or) from the difference in the form of oil supplements (free oil vs. seeds).

Vaccenic acid concentration in effluent also increased as SDR increased. The effect of SDR on VA concentration may have resulted from the reduction in digesta retention time. Higher SDR decrease the opportunity for complete $\mathrm{BH}$ and therefore may increase the flow of $\mathrm{BH}$ intermediates. Approximately $80 \%$ of FA in the rumen are associated with rumen digesta (Harfoot and Hazlewood, 1988). The increase in VA concentration with high SDR may also be due to a shift in the bacterial 
population or bacterial enzyme activity. Low dilution rate was shown to have a negative effect on microbial growth (Martin et al., 2002), particularly on growth of cellulolytic bacteria (Latham et al., 1972). Crawford et al. (1980a) reported a significant drop in protozoa number in continuous fermenters as solids retention time decreased. Additionally, microbial protein synthesis also decreased as solids retention time increased (Crawford et al., 1980b). Using continuous cultures, Hoover et al. (1984) showed that, at a $0.04 \% / \mathrm{h}$ dilution rate, lactic acid accounted for 53\% of all organic acids, but as dilution rate increased to $0.08 \% / \mathrm{h}$, lactic acid was reduced to $28 \%$. A further increase in dilution rate decreased lactic acid to $8 \%$. The low dilution rate may modify the distribution (number, species) of cellulolytic bacteria colonizing the plant material. Cellulolytic bacteria, such as Butyrivibrio fibrisolvens, are indeed the main ruminal bacteria responsible for $\mathrm{BH}$ (Harfoot and Hazlewood, 1988). Additionally, at low dilution rate, the "balance" of microorganisms capable of carrying out various steps of $\mathrm{BH}$ may be altered, leading to changes in production of $\mathrm{BH}$ intermediates.

The concentration of $c 9 t 11$ CLA was very low $(<1 \%)$ in effluent relative to trans $\mathrm{C} 18: 1(\sim 31 \%)$. Piperova et al. (2002) reported a flow of 0.24 to $0.53 \mathrm{~g} / \mathrm{d}$ of $c 9 t 11$ CLA compared with 57 to $120 \mathrm{~g} / \mathrm{d}$ for trans C18:1. Similar $c 9 t 11$ CLA flow results were reported in steers $(0.63$ to $1.2 \mathrm{~g} / \mathrm{d}$; Sackmann et al., 2003) and in sheep (0.12 to $0.20 \mathrm{~g} / \mathrm{d}$; Kucuk et al., 2001). The studies of Harfoot and Hazlewood (1988) have shown that $c 9 t 11$ CLA is rapidly metabolized in the rumen, and trans $\mathrm{C} 18: 1$ accumulates during unsaturated FA BH. The higher concentration of $c 9 t 11$ CLA with SBO treatments seen in this study is consistent with the findings of others (Loor et al., 2005; AbuGhazaleh and Jacobson, 2007). AbuGhazaleh et al. (2003a,b) showed that the increase in milk and rumen $c 9 t 11$ CLA concentration is higher when diets with a high concentration of linoleic acid rather than linolenic acid are supplemented with FO. When LSO and sunflower oil were included in the diet of dairy cows at $5 \%$ of diet DM; the duodenal flow of $c 9 t 11$ CLA with the sunflower oil diet was several fold higher compared with the LSO diet (Loor et al., 2005). The $c 9 t 11$ CLA is an intermediate during the $\mathrm{BH}$ of linoleic acid, but not linolenic acid (Harfoot and Hazlewood, 1988). As with VA, increasing SDR increased the concentration of $c 9 t 11$ CLA in effluent. Similarly, Martin and Jenkins (2002) observed a greater increase in $c 9 t 11$ CLA concentration in fermenters maintained at $0.10 \%$ / $\mathrm{h}$ LDR compared with fermenters maintained at $0.05 \% /$ $\mathrm{h}$. The $c 9 t 11$ CLA is a transient intermediate during $\mathrm{BH}$, and any increase in digesta rate of passage would potentially increase outflow.
The BH of linolenic acid increased with LSO supplementation. Other studies have also reported an increase in the $\mathrm{BH}$ of linolenic acid when linolenic acid source is used (Troegeler-Meynadier et al., 2003; Loor et al., 2004a). Linolenic is thought to be more toxic to rumen microbes and may be preferentially biohydrogenated more rapidly. Biohydrogenation of unsaturated C18 FA increased as SDR decreased. With a prolonged retention time, substrate would be available for a greater period for $\mathrm{BH}$.

The greater concentration of hydroxy and keto stearic acids seen in the effluent of SBO diets resulted from the higher oleic acid content in SBO diets (Table 2). Recently, Jenkins et al. (2006) showed that the accumulation of hydroxy and keto stearic acids in the rumen is related to oleic acid input. AbuGhazaleh et al. (2005) showed that rumen microbes not only can biohydrogenate the double bond in oleic acid, but also can hydrate it, forming hydroxy and keto stearic acids. The biological and physiological consequences of consumption of hydroxy and keto stearic acids by humans are currently being examined.

\section{CONCLUSIONS}

Results from this experiment indicate that dietary oil source and SDR influence the production of VA and $c 9 t 11$ CLA in the rumen. Higher concentrations of VA and $c 9 t 11$ CLA are seen when a linoleic, rather than a linolenic acid, oil source is used in a diet containing FO. These results also show that reducing retention time of ruminal digesta increases VA and $c 9 t 11$ CLA outflow. This study demonstrated that the best approach to increase ruminal VA and $c 9 t 11$ CLA production, and potentially $c 9 t 11$ CLA levels in ruminant food products, is to combine a high ruminal SDR with a linoleic acid oil.

\section{REFERENCES}

AbuGhazaleh, A. A., and B. N. Jacobson. 2007. The effect of $\mathrm{pH}$ and polyunsaturated $\mathrm{C} 18$ fatty acid source on the production of vaccenic acid and conjugated linoleic acids in ruminal cultures incubated with docosahexaenoic acid. Anim. Feed Sci. Technol. doi:10.1016/j.anifeedsci.2006.08.020

AbuGhazaleh, A. A., and T. C. Jenkins. 2004. Short communication: Docosahexaenoic acid promotes vaccenic acid accumulation in mixed ruminal cultures when incubated with linoleic acid. J. Dairy Sci. 87:1047-1050.

AbuGhazaleh, A. A., M. B. Riley, and T. C. Jenkins. 2005. The effect of $\mathrm{pH}$ and dilution rate on the conversion of stable isotopically labeled oleic acid to trans monoenes in continuous cultures. J. Dairy Sci. 88:4334-4341.

AbuGhazaleh, A. A., D. J. Schingoethe, A. R. Hippen, and K. F. Kalscheur. 2003a. Conjugated linoleic acid and vaccenic acid in rumen, plasma, and milk of cows fed fish oil and fats differing in saturation of 18 carbon fatty acids. J. Dairy Sci. 86:3648-3660.

AbuGhazaleh, A. A., D. J. Schingoethe, A. R. Hippen, and K. F. Kalscheur. 2003b. Milk conjugated linoleic acid response to fish 
oil supplementation of diets differing in fatty acid profiles. J. Dairy Sci. 86:944-953.

AbuGhazaleh, A. A., D. J. Schingoethe, A. R. Hippen, and L. A. Whitlock. 2002. Feeding fish meal and extruded soybeans enhances the conjugated linoleic acid (CLA) content of milk. J. Dairy Sci. 85:624-631.

AOAC. 1997. Official Methods of Analysis. 16th ed. Association of Official Analytical Chemists, Gaithersburg, MD.

Bauman, D. E., B. A. Corl, L. H. Baumgard, and J. M. Griinari. 2001 Conjugated linoleic acid (CLA) and the dairy cow. Pages. 221250 in Recent Advances in Animal Nutrition. P. C. Garnsworthy and J. Wiseman, ed. Nottingham University Press, Nottingham, UK.

Chouinard, P. Y., L. Corneau, W. R. Butler, Y. Chilliard, J. K. Drackley, and D. E. Bauman. 2001. Effect of dietary lipid source on conjugated linoleic acid concentrations in milk fat. J. Dairy Sci. 84:680-690.

Chow, T. T., V. Fievez, A. P. Moloney, K. Raes, D. Demeyer, and S. De Smet. 2004. Effect of fish oil on in vitro rumen lipolysis, apparent biohydrogenation of linoleic and linolenic acid and accumulation of biohydrogenation intermediates. Anim. Feed Sci. Technol. $117: 1-12$.

Crawford, R. J., W. H. Hoover, and L. L. Junkins. 1980a. Effects of solids and liquid flows on fermentation in continuous cultures. II. Nitrogen partition and efficiency of microbial synthesis. J. Anim. Sci. 51:986-995.

Crawford, R. J., W. H. Hoover, and P. H. Knowlton. 1980b. Effects of solids and liquid flows on fermentation in continuous cultures. I. Dry matter and fiber digestion, VFA production and protozoa number. J. Anim. Sci. 51:975-985.

Dhiman, T. R., L. D. Satter, M. W. Pariza, M. P. Galli, K. Albright, and M. X. Tolosa. 2000. Conjugated linoleic acid (CLA) content of milk from cows offered diets rich in linoleic and linolenic acid. J. Dairy Sci. 83:1016-1027.

Harfoot, C. G., and G. P. Hazlewood. 1988. Lipid metabolism in the rumen. Pages 285-322 in The Rumen Microbial Ecosystem. P. N. Hobson, ed. Elsevier Applied Science Publishers, London, UK.

Hoover, W. H., C. R. Kincaid, G. A. Varga, W. V. Thayne, and L. L. Junkins. 1984. Effects of solids and liquid flows on fermentation in continuous cultures. IV. $\mathrm{pH}$ and dilution rate. J. Anim. Sci. 58:692-699.

Isaacson, H. R., F. C. Hinds, M. P. Bryant, and F. N. Owens. 1975. Efficiency of energy utilization by mixed rumen bacteria in continuous culture. J. Dairy Sci. 58:1645-1659.

Jenkins, T. C., A. A. AbuGhazaleh, S. Freeman, and E. J. Thies. 2006. The production of 10-hydroxystearic and 10-ketostearic acids is an alternative route of oleic acid transformation by the ruminal microbiota in cattle. J. Nutr. 136:926-931.

Kelly, M. L., J. R. Berry, D. A. Dwyer, J. M. Griinari, P. Y. Chouinard, M. E. Van Amburgh, and D. E. Bauman. 1998. Dietary fatty acid sources affect conjugated linoleic acid concentrations in milk from lactating dairy cows. J. Nutr. 128:881-885.

Kramer, J. K. G., V. Fellner, M. E. R. Dugan, F. D. Sauer, M. M. Mosoba, and M. P. Yurawecz. 1997. Evaluating acid and base catalysts in the methylation of milk and rumen fatty acids with special emphasis on conjugated dienes and total trans fatty acids. Lipids 32:1219-1228.
Kucuk, O., B. W. Hess, P. A. Ludden, and D. C. Rule. 2001. Effect of forage:concentrate ratio on ruminal digestion and duodenal flow of fatty acids in ewes. J. Anim. Sci. 79:2233-2240.

Latham, M. J., J. E. Storry, and M. E. Sharpe. 1972. Effects of lowroughage diets on the microflora and lipid metabolism in the rumen. Appl. Microbiol. 24:871-877.

Loor, J. J., K. Ueda, A. Ferlay, Y. Chilliard, and M. Doreau. 2004a. Biohydrogenation, duodenal flow, and intestinal digestibility of trans fatty acids and conjugated linoleic acids in response to dietary forage:concentrate ratio and linseed oil in dairy cows. J. Dairy Sci. 87:2472-2485.

Loor, J. J., K. Ueda, A. Ferlay, Y. Chilliard, and M. Doreau. 2005. Intestinal flow and digestibility of trans fatty acids and conjugated linoleic acids (CLA) in dairy cows fed a high-concentrate diet supplemented with fish oil, linseed oil, or sunflower oil. Anim. Feed Sci. Technol. 119:203-225.

Loor, J. J., K. Ueda, A. Ferlay, Y. Chilliard, and M. Doreau. 2004b. Short communication: Diurnal profiles of conjugated linoleic acids and trans fatty acids in ruminal fluid from cows fed a high concentrate diet supplemented with fish oil, linseed oil, or sunflower oil. J. Dairy Sci. 87:2468-2471.

Martin, S. A., G. Fonty, and B. Michalet-Doreau. 2002. Factors affecting the fibrolytic activity of the digestive microbial ecosystems in ruminants. Pages 1-17 in Gastrointestinal Microbiology in Animals. S. A. Martin, ed. Research Signpost, Trivandrum, India.

Martin, S. A., and T. C. Jenkins. 2002. Factors affecting conjugated linoleic acid and trans-C18:1 fatty acid production by mixed ruminal bacteria. J. Anim. Sci. 80:3347-3352.

Qiu, X., M. L. Eastridge, K. E. Griswold, and J. L. Firkins. 2004. Effects of substrate, passage rate, and $\mathrm{pH}$ in continuous culture on flows of conjugated linoleic acid and trans C18:1. J. Dairy Sci. 87:3473-3479

Piperova, L. S., J. Sampugna, B. B. Teter, K. F. Kalscheur, M. P. Yurawecz, Y. Ku, K. M. Morehouse, and R. A. Erdman. 2002 Duodenal and milk trans octadecenoic acid and conjugated linoleic acid (CLA) isomers indicate that postabsorptive synthesis is the predominant source of cis-9-containing CLA in lactating dairy cows. J. Nutr. 132:1235-1241.

Sackmann, J. R., S. K. Duckett, M. H. Gillis, C. E. Realimi, A. H. Parks, and R. B. Eggelston. 2003. Effects of forage and sunflower oil levels on ruminal biohydrogenation of fatty acids and conjugated linoleic acid formation in beef steers and finishing diets. J. Anim. Sci. 81:3174-3181.

Stern, M. D., and W. H. Hoover. 1990. The dual flow continuous culture system. Pages 17-32 in Continuous Culture Fermenters: Frustration or Fermentation? Workshop Handbook for Northeastern ADSA-ASAS Regional Meeting, Chazy, NY.

Troegeler-Meynadier, A., M. C. Nicot, C. Bayourthe, R. Moncoulon, and F. Enjalbert. 2003. Effects of $\mathrm{pH}$ and concentration of linoleic and linolenic acids on extent and intermediates of ruminal biohydrogenation in vitro. J. Dairy Sci. 86:4054-4063.

Ward, A. T., K. M. Wittenberg, and R. Przybylski. 2002. Bovine milk fatty acid profiles produced by feeding diets containing solin, flax and canola. J. Dairy Sci. 85:1191-1196.

Weller, R. A., and A. F. Pilgrim. 1974. Passage of protozoa and volatile fatty acids from the rumen of sheep and from a continuous in vitro fermentation system. Br. J. Nutr. 32:341-352. 